\title{
Exploring Psychosocial Support Online: A Content Analysis of Messages in an Adolescent and Young Adult Cancer Community
}

\author{
Brad Love, Ph.D., Brittani Crook, M.A., ${ }^{2}$ Charee M. Thompson, M.A., ${ }^{2}$ Sarah Zaitchik, M.A., ${ }^{2}$ \\ Jessica Knapp, M.A., ${ }^{2}$ Leah LeFebvre, M.A., ${ }^{2}$ Barbara Jones, Ph.D., M.S.W., ${ }^{3}$ Erin Donovan-Kicken, Ph.D., ${ }^{2}$ \\ Emily Eargle, M.S.W., ${ }^{4}$ and Ruth Rechis, Ph.D. ${ }^{4}$
}

\begin{abstract}
The increased usage of online cancer support groups as a resource for health-related information and social support has sparked numerous discussions about the role of online support in healthcare. However, little is known about the role of social-networking groups focused on supporting adolescents and young adults (AYAs) dealing with cancer. The current investigation report findings from a content analysis designed to explore how AYAs use an online support group to meet their psychosocial needs. Overall, members of the community focused on exchanging emotional and informational support, coping with difficult emotions through expression, describing experiences of being an AYA dealing with cancer through language (metaphors), enacting identity through evaluations of the new normal (life with and after cancer), and communicating membership as an AYA with cancer. This study highlights the unique needs of the AYA cancer community and offers a preliminary roadmap for practitioners, and network members, such as family and friends, to attempt to meet the needs of this unique community.
\end{abstract}

\section{Introduction}

$\mathbf{H}$ EALTH PROFESSIONALS and patient advocates increasingly recognize the importance of harnessing people's desire to connect online to spread health information and provide support, with one in five Internet users searching for others sharing similar health concerns. ${ }^{1-7}$ Online communities are not "information vending machines,"1 but sites where individuals exchange information as well as provide emotional support and develop relationships ${ }^{1,8,9}$ such that individuals become better able to cope, ${ }^{9,10}$ feel more confident in their knowledge, and experience better health outcomes. $^{8-10}$

With young adults living increasingly digital lives, ${ }^{11-13}$ online support presents opportunities to provide much-needed resources to those seeking them. As health-information research suggests, "with Internet usage so prevalent among teenagers and young adults, development of age-appropriate web-based resources has great potential," especially in youth-focused areas like adolescent and young adult (AYA) oncology. ${ }^{14}$ AYAs affected by cancer are important to study because their health outcomes have not improved in decades for many cancers, and a lack of age-specific support plays a central role in these outcomes. ${ }^{15-19}$ AYAs grapple with issues related to identity and development, including body image, reproduction, romantic relationships, information management, and careers. ${ }^{15,20}$ More than 50 percent of AYAs report unmet information and service needs. ${ }^{14}$

Despite research advances, little attention has been paid to the role of social-networking in supporting AYAs affected by cancer. Empirical, effect-focused research examining cancer-related online support concentrates on a few cancers with minimal examination of broader diagnoses or demographics, ${ }^{10,21,22}$ as is being done here. The current study is an important extension, because it addresses the role messages play in online peer support for a population with well-documented support needs. To assess what is being communicated in an online community for those affected by cancer, this study addresses the research question: what are the types of messages related to psychosocial needs being shared within the community?

\footnotetext{
Data from this project were presented at the Association of Oncology Social Work Annual Conference in May, in Boston, Massachusetts.

${ }^{1}$ Department of Advertising and Public Relations, College of Communication, University of Texas, Austin, Texas.

${ }^{2}$ Department of Communication Studies, College of Communication, University of Texas, Austin, Texas.

${ }^{3}$ University of Texas, School of Social Work and The Institute for Grief, Loss and Family Survival, Austin, Texas.

${ }^{4}$ The Lance Armstrong Foundation, Austin, Texas.
} 
Method

Sample

With the Institutional Review Board approval and cooperation from managers, data from a cancer support forum were compiled from de-identified text-only files of full conversation threads, including initial posts and reactions. The forum is open to any young adult affected by cancer across the treatment spectrum. The unit of analysis for the study was "speech events," described below, and the sampling frame included text from 350 randomly sampled posts composed of 33,040 words from 2007 to 2010. Researchers ceased drawing additional, random posts once the team reached saturation and no new communication goals (defined as "culturally viable explanations" for behavior ${ }^{23}$ ) emerged. ${ }^{24,25}$

\section{Data analysis}

Communication goals related to psychosocial needs were analyzed per "speech events," 26 episodes of communication characterized by internal unity, containing a clear beginning and ending, and seen as pursuing commonly understood goals. "27 "Speech events" are a basic building block of human communication $^{27,28}$ delineated as each time a user participates in discourse to achieve a particular goal. Their socially agreed upon nature helps study and explain the "meaning and structure" of basic activities. ${ }^{27}$

Because individuals can pursue multiple communication goals within a single sentence or post, ${ }^{27,29}$ using speech events as the unit of analysis ensured that our study accurately captured the types of talk emerging through natural conversation within this community, as speech events can range from a few words to many sentences. While shorter speech events employ several words to meet a communication goal ("Please help!" as a support-seeking speech event), longer speech events can require several sentences or an entire post, as long as that post focuses on a single communication goal (a user seeking informational support by matter-of-factly discussing his diagnosis for a paragraph before requesting advice on next steps).

Examining content at only the sentence level could miss nuances or omit simultaneous goal-seeking (a user venting and seeking support: "This makes me crazy, and I could use help from you guys"); by focusing on the distinctions between different types of speech events, our research provides a more holistic picture of the dialogue within the online community.

Coders worked by reading each thread and noting speech events within each post, marking presence or absence of the types of talk discussed below.

\section{Procedure}

Speech events were analyzed with a coding guide built by combining key findings from a review of typologies and summary pieces concerning communication goals (see Table 1). ${ }^{23,27,29}$ Constructs were discussed by researchers, tested within the text, and adapted for the online context and types of speech likely to occur. Interpretative validity ${ }^{30}$ was assessed through triangulation by comparing multiple sources: specifically, comparing our findings to four AYAoncology-centered focus groups conducted for a different study and reading two additional, independent cancersupport websites.
Table 1. Frequency of Types of Talk

\begin{tabular}{lcc}
\hline Types of talk & $\begin{array}{c}\text { No. of } \\
\text { appearances }\end{array}$ & \% of total \\
\hline Exchanging support & 390 & 47.91 \\
Emotional support & 221 & 27.15 \\
Informational support & 128 & 15.72 \\
Esteem support & 41 & 5.03 \\
Coping & 203 & 24.94 \\
Humor & 100 & 12.29 \\
Venting/emotional expression & 71 & 8.72 \\
Silver linings & 32 & 3.93 \\
Describing experiences & 88 & 10.81 \\
Metaphors & 44 & 5.41 \\
Euphemisms & 39 & 4.79 \\
Stereotypes & 5 & 0.61 \\
Enacting identity & 74 & 9.1 \\
Biological disruption & 31 & 3.80 \\
Locus of control & 17 & 2.1 \\
Personal narrative & 16 & 2.0 \\
Performance of cancer & 10 & 1.23 \\
Communicating membership & 60 & 7.37 \\
In/out group & 26 & 3.19 \\
Establishing membership & 22 & 2.70 \\
Renewing through anniversary & 12 & 1.47 \\
Total & 815 & \\
\hline
\end{tabular}

\section{Evaluation of the coding guide}

Research team members completed several months of training to develop the coding guide and achieve intercoder agreement on the presence or absence of communication goals. Initial training consisted of open reading ${ }^{30,31}$ of several complete threads and group conversations regarding goals. From this, team leaders selected the most essential communication goals occurring in the data. Coders practiced with the guide to achieve reliability on the presence of communication exchanges, registering presence or absence for relative frequencies. Intercoder reliability using Krippendorff's alpha ranged from 0.80 to 1 across four coders. Differences were resolved by the first author.

\section{Results}

\section{Frequency of types of talk}

The research team examined speech events, noting relative frequencies of communication goals and topics communicated by users. The 16 types of talk were grouped into five supracategories representing frequent themes: exchanging support (47.91 percent), coping (24.94 percent), describing experiences (10.81 percent), enacting identity (9.1 percent), and communicating membership (7.37 percent). The frequency of each type of talk is shown in Table 1 . The most prominent types of talk and key conversational themes are discussed below.

Exchanging support. Emotional support exchanges typically included conversations where members related, provided perspectives, or offered understanding. This most common type of talk centered on treatment, medication, and relationships. Community members tended to offer empathy 
to convey mutual understanding through stories, thoughts, and feelings ("The same thing happened to me."). Support developed as a cyclical process whereby one member asked for affirmation ("Am I alone in feeling this angry?"), and then others shared-or at least validated the feelings ("My situation was different, but I understand how you must feel"). Supporting the original poster seemed to serve a cathartic function. By giving support, members received support, contributing to the constructive environment.

Sharing informational support appeared as messages sharing or soliciting knowledge, often about personal experience with treatment, medications, and diet and exercise. Many contributors discuss the forum as an approximate second opinion. Experiences of others appeared to be a trusted source largely treated as separate from health professionals' directives. The popular advice episodes involved: treatment types and side effects, doctor and treatment facility reviews, mental health concerns, and relational issues (troubles with dating, talking to close others about thoughts and feelings).

Coping. Across all types of talk, coping with emotions emerged as a frequent subject. Through humor, positive reframing, or venting, coping involves emotional and informational support. Members joked with each other and laughed at themselves to combat the expressed overwhelming feelings of fear, anger, sadness, and loneliness. For example, one thread entitled "What pisses you off?" included members venting frustrations. Common frustrations included: insensitive or assuming comments from others ("A police man told him he looked pretty good for being sick. He looked at him and paused for a second, then said, "Thank you, but the tumors are on the inside."').

Members reframed some of the most difficult experiences as positive ones to cope. A silver lining helped make sense of their experiences, attribute meaning, and see it as something that has made life better, not worse-even if it did not feel that way at times. For example, one wrote, "But my thought is if I can help someone else, even just one person, by sharing my story and/or my time, that I'm getting outside myself and somehow helping to make the world a slightly better place for the limited time I'm here."

Users maintained almost uniform positivity. Positivity and hope persisted even when members were venting or discussing difficult topics, such as the termination of relationships. Contributors fostered this behavior by encouraging people to recognize their lovability or attractiveness, resulting in a community comfortable discussing serious matters in a supportive and realistic tone.

Describing experiences. AYAs in this community used metaphorical and euphemistic language to refer to themselves, their cancer, and their experiences. When speaking euphemistically, individuals referred to "cancer" as ambiguous descriptions of cancer meaning the same thing, including "lump," "growth," "dark spot," and "seedlings." Losing hair was a "hair cut," and when it grew back, a "perm." Treatment was described as "a bike that requires your legs to move it into a purposeful direction." In one thread entitled, "Dear Cancer: What would you say to your cancer?" members addressed their cancer as a living person. Using sarcasm, one AYA said, "There's bad blood between us now (haha) and I just want to say that I'll beat your face in with my first if you ever come near me again." Another wrote, "So you see my old little buddy, although I wish you had never come into my life, I do not regret what has happened to me."

Enacting identity. Cancer was described as a hugely disruptive force that, like a whirlwind, swept in unexpectedly and after treatment often left just as abruptly, initially causing devastation. In general, members reported a dearth of support on how to manage life after cancer, accepting that cancer has changed them forever and restructuring a life they want to live. They struggled to make sense of their personal journeys and self-identities.

These needs are amplified by the way individuals talk about their cancer experience, namely, through personal stories. For example, in one thread about the difficulty of disclosing cancer to a potential romantic partner about cancer, many shared the story of how they told someone they were interested in. Other stories are about the cancer journey from life before cancer to life post-treatment. In the end, once treatment ends, many members report struggling with depression, strained relationships, and maladjustment to work, although others describe a more meaningful outlook.

Communicating membership. One community-building function of the online support group involves talk that signifies who is and is not a member of the community. The first theme, establishing membership, occurred when individuals legitimized their presence on the site by stating reasons for use. This typically included background information and served as a way for individuals to introduce themselves to the community.

Often, AYAs discussed noncancer patients as out-group members because they could never understand having cancer. In addition, AYAs signal closeness to other community members - the in-group-by showing appreciation and giving compliments. For example, one said, "I have found that this site has been undeniably the most helpful thing for me... I am so glad I found this site."

\section{Discussion}

Our findings suggest that life during and after cancer for AYAs is a negotiation of lessons learned and strength gained with struggles to meet expectations of self and others, as well as recovery from the trauma of diagnosis and treatment. Our research purpose was to understand what AYAs were discussing in this online forum. Broadly speaking, AYAs exchange support, cope, use particular language to describe experiences, enact identity, and communicate membership. AYAs exchange two primary types of support, information and emotional, through providing advice and empathizing with others. Coping with emotions involved the various strategies AYAs use to deal with cancer, including venting and using humor and optimism. AYAs in this study also used various forms of language (euphemisms, metaphors, and stereotypes) to talk about themselves and cancer. Last, communicating membership was an important feature of this community, likely because of the sensitive nature of their common experiences and unique perspectives. Sharing personal feelings and stories requires trust that members find in each other, but are careful to protect through signaling in/out group status. 
These findings point to the specific needs of the AYA cancer community and are important because they offer a foundational understanding of what individuals are discussing online. In addition, the results of our study offer initial guidance about how healthcare providers and caregivers can attempt to meet the needs of young adults affected by cancer. The online support community appeared to be an impressive support asset, evidenced by the frequency, volume, and type of support provided within the forums, as well as how often members outwardly praised it. Promotion of online support through care providers could bring in additional, in-need individuals.

Further, finding needed content at the appropriate time seems to be the challenge. ${ }^{14}$ Young adults would likely benefit from specialized resources to help them with early and late phases of their cancer experiences, particularly with aspects that are important at this emerging adult stage of life, such as romantic relationships, reproduction, identity development, and control over one's life and decisions. Ultimately, we hope these findings will help refine and improve valuable resources like online support communities, as better digital health promotion resources can enhance health outcomes and quality of life for young adults by meeting their age-specific knowledge and peer-support needs.

\section{Acknowledgments}

The authors wish to acknowledge the support of the Lance Armstrong Foundation, which provided funding for this research. We would also like to thank Jason Moore, M.S., for his help in data organization and management.

\section{Author Disclosure Statement}

No competing financial interests exist.

\section{References}

1. Fox S. (2010) Cancer 2.0: a summary of recent research. http://pewrsr.ch/Cancer20 (accessed May 9, 2012).

2. Adams H. Planet cancer: a community of young adults with cancer. Journal of Oncology Practice 2008; 4:189.

3. Crespo R. Virtual community health promotion. Preventing Chronic Disease July 2007. http://www.cdc.gov/pcd/ issues/2007/jul/07_0043.htm (accessed May 9, 2012).

4. Gustafson DH, McTavish FM, Stengle W, et al. Use and impact of eHealth system by low-income women with breast cancer. Journal of Health Communication 2005; 10: 195-218.

5. Murray S, Giustini D, Loubani T, et al. Medical research and social media: can wikis be used as a publishing platform in medicine? Open Medicine 2009; 3. www.openmedicine.ca/ rt/printerFriendly/332/248 (accessed May 9, 2012).

6. Shaw B, Gustafson DH, Hawkins R, et al. How underserved breast cancer patients use and benefit from eHealth programs: implications for closing the digital divide. American Behavioral Scientist 2006; 49:823-834.

7. Whitten $\mathrm{P}, \mathrm{Mackert} \mathrm{M}$, Love $\mathrm{B}$, et al. Internet generation by disparities: ensuring low-literate adult access to online health information. Presented at Association of Internet Researchers, Chicago, IL, October 2005.

8. van Uden-Kraan CF, Drossaert CHC, Taal E, et al. Participation in online partient support groups endorses patients' empowerment. Patient Eucation and Counseling 2009; 74:61-69.

9. Rodgers $\mathrm{S}, \mathrm{Chen} \mathrm{Q}$. Internet community group participation: psychosocial benefits for women with breast cancer. Journal of Computer-Mediated Communication 2005; 10:article 5. http://jcmc.indiana.edu/vol10/issue4/rodgers .html (accessed May 9 2012).

10. Beaudoin $\mathrm{CE}, \mathrm{Tao}, \mathrm{C}$. Benefiting from social capital in online support groups: an empirical study of cancer patients. CyberPsychology and Behavior 2007; 10:587-590.

11. O'Malley G. Everybody likes to watch: $90 \%$ of young adults use video-sharing sites. Online Media Daily July 29, 2009. www.mediapost.com/publications $/ ? \mathrm{fa}=$ Articles.showArticle \&art_aid=110640 (accessed May 9, 2012).

12. Pew Research Center. (2007) How young people view their lives, futures, and politics: a portrait of "Generation Next." Washington, DC: Pew Research Center for the People and the Press.

13. Vance K, Howe W, Dellavalle R. Social Internet sites as a source of public health information. Dermatologic Clinics 2009; 27:133-136.

14. Zebrack B. Information and service needs for young adult cancer survivors. Support Care Cancer 2009; 17:349-357.

15. Haase JE, Phillips CR. The adolsecent/young adult experience. Journal of Pediatric Oncology Nursing 2004; 21: 145-149.

16. Bleyer A. Latest estimates of survival rates of the 24 most common cancers in adolescent and young adult Americans. Journal of Adolescent and Young Adult Oncology 2011; 1:37-42.

17. Fernandez, C, Fraser, GAM, Freeman, C, et al. The Canadian task force on adolescents and young adults with cancer. Journal of Adolescent and Young Adult Oncology 2011; 1:53-59.

18. Ramphal R, Meyer R, Schacter B, et al. Active therapy and models of care for adolescents and young adults with cancer. Cancer 2011; 117(10 Suppl):2316-2322.

19. Epplein M, Zheng $\mathrm{Y}$, Zheng W, et al. Quality of life after breast cancer diagnosis and survival. Journal of Clinical Oncology 2011; 29:406-412.

20. Zebrack B. Psychological, social, and behavioral issues for young adults with cancer. Cancer 2011; 117(10 Suppl):22892294.

21. Hong Y, Pena-Purcell N, Ory M. Outcomes of online support and resources for cancer survivors: a systematic literature review. Patient Education and Counseling 2012; 86:288-296.

22. Im E. Online support of patients and survivors of cancer. Seminars of Oncology Nursing 2011; 27:229-236.

23. Dillard JP. Type of influence goals in personal relationships. Journal of Social and Personal Relationships 1989; 6:293-308.

24. Riffe D, Lacy S, Fico F. (2005) Analyzing media messages. Mahwah, NJ: Lawrence Erlbaum Associates.

25. Francis JJ, Johnston M., Robertson C, et al. What is an adequate sample size? Operationalising data saturation for theory-based interview studies. Psychology and Health 2010; 25:1229-1245.

26. Watzlawick P, Beavin J, Jackson D. (1967) Pragmatics of human communication. New York: W. W. Norton.

27. Goldsmith DJ, Baxter LA. Constituting relationships in talk: a taxonomy of speech events in social and personal relationships. Human Communication Research 1996; 23: 87-114.

28. Saville-Troike M. (1989). The ethnography of communication. 2nd ed. New York: Basil Blackwell. 
29. Wilson SR. (2002) Second generation: persuasive message production as goal pursuit. In Wilson SR, ed. Seeking and resisting compliance: why people say what they do when trying to influence others. Thousand Oaks, CA: Sage Publications, pp. 133-180.

30. Lindlof TR, Taylor BC. (2002) Qualitative communication research methods. Thousand Oaks, CA: Sage.

31. Bulmer M. Concepts in the analysis of qualitative data. Sociological Review 1979; 27:651-677.
Address correspondence to: Dr. Brad Love Department of Advertising and Public Relations Belo Center for New Media The University of Texas at Austin

BMC 4.342

300 W. Dean Keeton St. Austin, TX 78712

E-mail: lovebrad@austin.utexas.edu 